Glaciological Society. Meetings are held at about three-monthly intervals in London, Cambridge and other places, and the papers with their discussions are printed and circulated in the Society's journal, which among other features contains a useful glaciological bibliography. Membership of the Society is open to all who have scientific, practical or general interest in any aspect of snow and ice study, and is by nomination. Further particulars may be obtained from the Assistant Secretary, British Glaciological Society, temporary address, c/o Royal Geographical Society, Kensington Gore, London, S.W.7.

\section{Scientific Background in China}

RECENT reports of the British Councu, in describing the work of its Cultural Scientific Office in Chungking, have given some account of the position of science in China, and still more factual accounts have been given by Dr. J. Needham in Nature (157, 175 ; 1946 , and 156,$496 ; 1945)$. In "Chinese Science" (London : Pilot Press, Ltd., pp. 80), Dr. Needham presents the background and setting in which scientific work is carried out in China, and the vivid contrast of old and new. There is little here to in. dicate research actually in progress in China or the results so far achieved by Chinese workers; there is much to indicate how important will be the future contribution from workers imbued with such resourcefulness and determination to overcome the handicaps under which they have been compelled to work. Few who read this admirably illustrated little volume can doubt that under the organisation already established, and which Dr. Needham outlines in his preface, Chinese research workers will speedily be making unique contributions in fields of their own, and that urgent as may be China's needs for equipment and supplies, even now the traffic will not be only one way. Four profusely illustrated chapters describe the position of scientific and educational institutions in Szechuan, in the northwest, the south-east and the south-west, and if the emphasis is on the workers and conditions rather than on the work being done, that may well enhance the appeal to the general reader to whom, rather than to the man of science, it is obviously addressed.

\section{Mechanism of Orogenesis and Volcanic Activity}

IN a pamphlet dealing with "The West Indies and the Mountain Uplift Problem" (privately printed by B. T. Ord, Ltd., West Hartlepool, 1945, pp. 25+6 figs.), Dr. C. T. Trechmann presents a short account of the geological structure and history of the West Indies, largely based on his own observations; and having found there a puzzling assemblage of phenomena, such as causes difficulty to geologists from time to time, he expresses his disbelief in the various hypotheses now on trial and offers alternative suggestions. Dr. Trechmann's attempt to account for orogenesis and vulcanism, with special reference to the West Indies, involves the following fallacious or demonstrably untenable ideas: (a) that ocean water at considerable depth penetrating unconsolidated or fragmentated conglomerates may induce metasomatism and generate heat by exothermic reactions; (b) that the floor of the Bartlett Trough may be lowered and that gaseous or magmatic and plastic material may be forced inwards and upwards beneath Jamaica and Cuba by the pressure due to four miles of sea water ; (c) that the upward tidal pull on emergent land may be cumulative, so inducing a landward flow of (sub-crustal magmatizing gases or liquids and thereby still further raising the land and deepening the adjacent sea floor. If Dr. Trechmann were able to visualize the kind of earth that would have resulted from the operation of the above alleged processes, he would find it strikingly at variance with the real earth with which geologists are concerned.

\section{Analysis of High-Purity Zinc and Zinc Alloys}

Physical methods of analysis, such as by the use of the polarograph or the spectrograph, are particularly suited to the determination of minute quantities of impurities in zinc and its alloys. A panel was appointed in 1941 by the Non-ferrous Industry Committee of the British Standards Institution to consider recommended methods for the polarographic and spectrographic analysis of high purity zinc and zinc alloys for die casting. The panel found in its review of earlier work that, though the spectrograph was used in certain laboratories, neither the details nor the precision of the technique was sufficiently defined to justify the immediate recommendation of a spectrographic method; the use of the polarograph was observed to be even less developed. The panel therefore planned, and had carried out by a number of interested organisations, a considerable amount of experimental work. An account of these investigations has been published under the title "Polarographic and Spectrographic Analysis of High Purity Zinc and Zinc Alloys for Die Casting" (H.M. Stationery Office, 1945). Based on this work, recommended methods have been prepared in order to enable comparative information to be collected. The recommendations of the panel, "Recommended Methods for Polarographic and Spectrographic Analysis of High Purity Zinc and Zine Alloys for Die Casting" (British Standard 1225; 1945. Pp. 36. 2s. net), are intended to be a guide and not a rigorously binding specification. The methods are effective, but, as the fields of analytical chemistry in which they lie are rapidly expanding, the Committee does not wish to impede development by strict rules. It is intended, therefore, to review the position at an early date in the light of further experience obtained by the use of these methods.

\section{The National Museum of Wales}

THe progressive activity of all departments of the National Museum of Wales is a striking feature of the report for the year 1944-45. Most of the material removed from the public exhibition galleries has now been restored and the reorganisation of certain parts of the collections is near completion. In accordance with the strong educational policy of the Museum, departmental lectures, gallery talks, demonstrations and special exhibitions have been provided throughout the year. The value of these is amply proved by the large attendance of students, teachers, classes of school-children and groups of Service men and women. Of the several public lectures given outside the Museum, mention may be made of a series of three given by the Keeper of the Department of Folk Culture and Industries to teachers at a Ministry of Education course held at Caerleon.

It is of further interest that the director of the Museum, after consultation with the Welsh Department of the Ministry of Education, prepared on behalf of the Council and at the request of the permanent secretary, a memorandum setting out the Museum's suggestions for a schools service. This document comprised : (1) a record and assessment 